\title{
Coroners' records on suicide mortality in Montréal: limitations and implications in suicide prevention strategies
}

\section{J. Houle, PhD; C. Guillou-Ouellette, BSc}

This article has been peer reviewed.

\begin{abstract}
Introduction: In Montréal, the characteristics of suicide cases may vary between different areas. The information collected by coroners during their investigations of suicides could be used to support local suicide-prevention planning actions.
\end{abstract}

Methods: This study analyzes all coroners' records on suicide in Montréal from 2007 to 2009 to (1) determine the usefulness of the data available; (2) develop a profile of cases; (3) examine local differences by comparing two areas, one with the highest suicide rate and the other with the lowest.

Results: The data collected revealed the lack of a systematic, standardized procedure for recording information about deaths by suicide. The rates of missing data varied, but were very high for antecedents of suicide attempts and recent events that could have precipitated the suicide. We observed differences in the characteristics of suicide cases according to area of residence.

Conclusion: By adopting a standardized procedure for collecting information on cases of suicide, coroners could provide local decision makers with a more accurate portrait of the people who die by suicide in their area. Local adjustments may improve suicideprevention strategies.

Keywords: suicide, coroner, prevention, surveillance

\section{Introduction}

Between 2000 and 2009, the suicide rate in Quebec fell significantly, from 16.8 per 100000 to 12.5 per 100000 , while the Canadian rate remained relatively stable, decreasing from 11.4 to 10.7 per $100000 .^{1,2}$ This decrease was not uniform in all population sub-groups. ${ }^{3}$ For example, the decrease in the suicide rate in youth aged 15 to 19 years was notable ( $10 \%$ in males and $14 \%$ in females), but in those aged 50 years plus, the suicide rate has remained relatively stable for both sexes. This suggests that existing suicide-prevention strategies targeting older adults need to be improved. Even if universal suicide-prevention strategies (e.g. means restriction) are effective, ${ }^{4}$ experts generally agree that it is necessary to implement selective suicide-prevention strategies that target specific populations at risk and take into account factors such as age, socioeconomic status, cultural norms and the social environment. ${ }^{5-8}$ Tailored interventions have proven effective at reducing suicide rates in older adults, ${ }^{5,9}$ police officers ${ }^{10}$ and the United States air force. ${ }^{11,12}$

Suicide rates in rural settings differ from those in urban settings. ${ }^{13}$ The densely populated areas of Laval and Montréal have the lowest suicide rates in the province of Quebec. In 2009, the suicide rate in the Montréal metropolitan area was
10.1 per $100000 .^{2,14}$ The Montréal metropolitan area is divided into 12 areas, each managed by a different health and social services centre (HSSC) with its own structure and set of services. With their community-based partners, for example, nongovernmental organizations and physicians, the HSSCs are responsible for implementing the most effective suicideprevention strategies. ${ }^{15}$

Montréal's health and social services agency (Agence de la santé et des services sociaux de Montréal, ASSS) provides the HSSCs with general statistics on suicide rates in their areas and on the links between these rates and other indicators. ${ }^{16}$ These statistics reveal considerable differences in the suicide rates in the different health service areas. For the period 2005 to 2009 , the adjusted rate of death by suicide for an HSSC in the centre of Montréal was 17.4 per 100 000, while that of an HSSC at in the west of the city was 5.1 per $100000 .{ }^{14}$ Although these statistics are useful, they are insufficient to prepare even a summary profile of suicide cases in each area as they do not allow for the sociodemographic characteristics of the deceased or the circumstances surrounding the deaths to be known. Furthermore, such a profile would probably vary from one HSSC area to another, implying that the preventative actions taken need to be adjusted at the local level.

In Quebec, in accordance with An Act Respecting the Determination of the Causes and Circumstances of Death, ${ }^{17}$ a coroner must identify the causes of all uncertain or violent deaths, including all cases of suicide. Each suicide is therefore subject

\section{Author references:}

Department of Psychology, Centre for Research and Intervention on Suicide and Euthanasia (CRISE), Université du Québec à Montréal, Montréal, Quebec, Canada

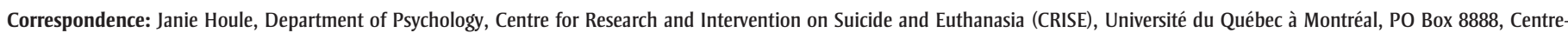
ville Branch, Montréal, QC H3C 3P8; Tel.: 514-987-3000 ext. 4751; Fax: 514-987-0350; Email: houle.janie@uqam.ca 
to an investigation conducted by one of the province's 85 coroners. Coroners are physicians, lawyers or notaries who must have a minimum of four years of professional experience to be part-time coroners and eight to be full-time. Coroners are appointed by the Quebec government after an extensive interview process and on being recommended by the Ministry of Public Security. The Montréal metropolitan area has 13 coroners, mostly part-time physicians $(\mathrm{n}=9)$ ).

When investigating a death by suicide, coroners need to produce an investigation report but are not provided with a template or any guidelines. Police officers often help in the investigation, and friends and family are almost always consulted. Coroners rarely conclude the cause of death as undetermined (less than $2 \%$ of investigations in 2009). The rate of underreported suicides is also believed to be so low that it does not affect the conclusions reached from analyzing coroners' reports. ${ }^{18}$ As sources of information, coroners' records are therefore crucial for developing a profile of suicide cases, though the Coroner's Office has never provided anything beyond a minimal analysis based on sex, age and methods of suicide for the cases in each area.

The purpose of this study is to explore the information on deaths by suicide in Montréal-area coroners' records to: (1) determine whether these data can be used at the local level to monitor suicide trends and support the development of suicideprevention strategies; (2) establish a comprehensive profile of suicide cases in 2007 through 2009; (3) examine local differences in the profile of suicide cases by comparing the two health service areas with the highest and lowest suicide rates.

The Chief Coroner's Office and Quebec's Ministry of Justice (Ministère de la Justice) reviewed and approved this research project before we began collecting our data.

\section{Methods}

\section{Population}

We included all residents of Montréal who, based on coroners' records, died in
2007, 2008 or 2009, and whose stated cause of death was death by suicide. Montréal is Quebec's economic hub, with close to 2 million inhabitants of diverse ethnicity and socioeconomic status. The HSSC area with the highest suicide rate (Area A) is in the downtown core and is one of the most populated neighbourhoods in Canada, with about 138500 residents. Area A is also very socially diverse and includes marginal populations, such as homeless people, prostitutes and drug addicts, as well as young professionals and families. ${ }^{19}$ The HSSC area with the lowest suicide rate (Area B) has about 217000 residents and some of the best living conditions in Montréal (based on socioeconomic status). The population from this area consists mostly of English-speaking families with high annual incomes compared to the average in Montréal. ${ }^{20}$

\section{Data sources}

Data for our study came from the complete records prepared for each suicide case and kept in the office of Quebec's Chief Coroner. A single researcher examined the coroner's investigative report, the official report on the police investigation and, where applicable, the suicide note, results of toxicological tests, medical records and any other relevant information. These records, which must be consulted on site, were subsequently verified by another researcher.

\section{Data collection form and variables}

Following an initial analysis of the coroners' investigative reports on deaths by suicide in 2009, we developed a data collection form. A researcher with many years' experience of collecting data from the Coroner's records subsequently revised this form. The final data collection form targeted the following information:

- Sociodemographic profile: Sex, age, marital status (single or cohabiting), parental status, employment status, household status (living alone or with others), the existence of financial problems or a criminal record, and postal code at the place of residence (HSSC area).
- Mental disorders: Psychiatric pathology (depression, substance abuse, schizophrenia, bipolar disorder, etc.) .

- Recent life events: Conjugal separation or loss of employment in the year before death.

- Suicidal behaviour: Any previous suicide attempts and the time between the previous attempt and the suicide death; suicidal verbalizations or behavioural changes suggesting a suicidal intent before the suicide death.

- Recent health services utilization: Professional assistance (physician, psychologist, HSSC, etc.) consulted in the year before death.

- Circumstances of death: Place (at home, in the workplace, etc.), the means used, whether a suicide note was found and signs of planning.

\section{Statistical analyses}

We used the statistical software SPSS version $\mathrm{X}$ for Windows (IBM, Chicago, IL, US). Data not mentioned in the coroner's file for a case were identified as missing. The frequency of missing data was calculated for each variable. We then established a profile of the suicide cases through a descriptive analysis (frequency, percentage) of the available data, excluding the missing data. For example, we calculated the percentage of suicide cases who were employed at the time of their death by dividing the number of cases employed at time of death by the total number of cases whose files indicated an employment status. Differences in sex were examined using Student's t-test for age and chi-square tests for the other variables. Finally, we used chi-square tests to determine the differences between the two HSSC areas, Area A and Area B.

\section{Results}

\section{Data available in the Coroner's records}

The data collected from the coroner's records revealed that there was no standard investigative procedure used for deaths by suicide. The rate of missing data varied considerably from one variable to the next (Table 1). Besides basic information such as sex, age, place of 
TABLE 1

Data on death by suicide missing from coroners' records, Montréal, Quebec, 2007-2009

\begin{tabular}{lc} 
Variable & $\begin{array}{c}\text { Missing data } \\
(\mathbf{N}=566)\end{array}$ \\
& $\mathbf{n}(\%)$ \\
\hline Sex & $0(0.0)$ \\
Age & $0(0.0)$ \\
Place of residence by postal code & $4(0.7)$ \\
Sociodemographic profile & \\
Not cohabiting & $16(2.8)$ \\
Unemployed & $71(12.5)$ \\
Childless & $54(9.5)$ \\
Living alone & $0(0.0)$ \\
Financial problems & $250(44.2)$ \\
Criminal record & $1(0.2)$ \\
Mental disorders & $3(0.5)$ \\
Physical illnesses & $3(0.5)$ \\
Recent life events ( 1 year) & \\
Job loss & $139(24.6)$ \\
Conjugal separation & $277(48.9)$ \\
Suicidal behaviours & \\
Previous attempt(s) & $243(42.9)$ \\
Previous attempt(s) within past year & $284(50.2)$ \\
Suicidal verbalizations & $84(14.8)$ \\
Changes in behaviour & $178(31.4)$ \\
Recent health services utilization $(\leq 1$ year) & $0(0.0)$ \\
Death circumstances & \\
Suicide note found & $23(4.1)$ \\
Signs of planning & $429(75.8)$ \\
Death at home & $1(0.2)$ \\
Method of suicide & $0(0.0)$ \\
\hline
\end{tabular}

suicide and means used-which were consistently noted in the records-other relevant information was not systematically recorded. For example, information on prior suicide attempts was missing from over $40 \%$ of the records.

\section{Profile of suicide cases in Montréal}

A total of 566 Montréal residents died by suicide in the years 2007, 2008 and 2009. The results show that $74.4 \%$ of the suicide deaths were among men and that over half $(52.3 \%)$ were aged 40 to 64 years (Table 2). Signs of social isolation-not cohabiting, unemployment, no children or living alone-were common. These signs tended to be cumulative: $55.0 \%$ of our subjects had three signs of social isolation while only $4.1 \%$ had none (data not shown). Many had at least one mental disorder (63.1\%), in particular depression $(32.3 \%)$ and substance abuse $(30.0 \%)$. Conjugal separation was the most commonly reported recent life event in the coroners' records $(13.6 \%)$. Three out of five cases $(59.9 \%)$ had consulted at least one source of professional assistance in the year before death, with family physicians $(35.7 \%)$ and psychiatrists $(27.7 \%)$ consulted most often.

Financial problems and criminal records were reported more often among men than among women. Women were more assistance in the year before their deaths. Women were also more likely to die by suicide at home. The means of suicide also varied by sex: hanging was more common likely to have consulted professional among men, while poisoning was more common among women (see Table 2).

\section{Comparison of HSSC areas with the lowest and highest suicide rates}

Compared with Area A, suicide cases in Area B experienced less social isolation: they were less likely to be living alone and more likely to be married or cohabiting and to have children (see Table 3). They were also less likely to have had a criminal record or recent financial problems or to have previously attempted suicide. The means used also differed: cases in Area A tended to use poisoning while cases in Area B tended to use strangulation.

\section{Discussion}

In this study we analyzed all the coroner's records of death by suicide in Montréal from 2007 to 2009 . Using a data extraction form, we combed through 566 files for information on suicide. In addition to establishing a profile of all the people who died by suicide, this process revealed the absence of a systematic, standardized procedure that coroners can use to collect information on death by suicide. The goal of our study was to examine the potential of coroners' files as a source of valid and useful information for local surveillance of suicide and planning of suicide-prevention actions. Given such a high rate of missing data and the lack of standardization in the coroners' practices, we cannot recommend that they be used for this purpose.

Many other studies-in Quebec, ${ }^{21}$ Canada $^{22}$ and the United States ${ }^{23}$ - have described the incomplete nature of the information collected by coroners. Many factors may explain the extent of the missing data. First, there is no standard method for drafting reports and collecting data for the official record. As a result, some coroners focus on looking for the causes of suicide, while others stop the investigation as soon as they have determined whether the cause of death was intentional, accidental or due to homicide. Finally, the absence of electronic health records in Quebec makes access to important medical data-such as a diagnosis of mental disorders or hospitalizations for 
TABLE 2

Profile of suicide cases, Montréal, Quebec, 2007-2009

\begin{tabular}{|c|c|c|c|c|}
\hline \multirow[t]{2}{*}{ Characteristic } & Total & $\begin{array}{c}\text { Female } \\
(n=145)\end{array}$ & $\begin{array}{c}\text { Male } \\
(n=421)\end{array}$ & \multirow[t]{2}{*}{$p$ value } \\
\hline & n (\%) & n (\%) & n (\%) & \\
\hline \multicolumn{5}{|l|}{ Age, years } \\
\hline $15-19$ & $18(3.2)$ & $5(3.4)$ & $13(3.1)$ & .831 \\
\hline $20-29$ & 79 (13.9) & $19(13.1)$ & $60(14.3)$ & .731 \\
\hline $30-39$ & $95(16.8)$ & $22(15.3)$ & $73(17.3)$ & .547 \\
\hline $40-49$ & $142(25.1)$ & $35(24.1)$ & $107(25.4)$ & .760 \\
\hline $50-64$ & $154(27.2)$ & $42(28.9)$ & $112(26.6)$ & .581 \\
\hline$\geq 65$ & 78 (13.8) & $22(15.2)$ & $56(13.3)$ & .573 \\
\hline \multicolumn{5}{|l|}{ Sociodemographic profile } \\
\hline Not cohabiting & $398(70.3)$ & $102(70.3)$ & $296(70.3)$ & .994 \\
\hline Unemployed & $334(59.0)$ & $91(62.8)$ & $243(57.7)$ & .900 \\
\hline Childless & $296(52.3)$ & $63(43.4)$ & $233(55.3)$ & .001 \\
\hline Living alone & 279 (49.3) & $71(48.9)$ & $208(49.4)$ & .927 \\
\hline Financial problems & $202(35.7)$ & $37(25.5)$ & $165(39.2)$ & .001 \\
\hline Criminal record & 112 (19.8) & $14(9.7)$ & $98(23.3)$ & .000 \\
\hline \multicolumn{5}{|l|}{ Mental disorders } \\
\hline At least one disorder & $357(63.1)$ & $101(69.7)$ & $256(60.1)$ & .038 \\
\hline Depression & $183(32.3)$ & 56 (38.6) & $127(30.2)$ & .058 \\
\hline Substance abuse & $170(30.0)$ & 40 (27.6) & $130(30.9)$ & .464 \\
\hline Bipolar disorder & $51(9.0)$ & $22(15.2)$ & $29(6.9)$ & .003 \\
\hline Schizophrenia & $48(8.5)$ & $13(9.0)$ & $35(8.3)$ & .803 \\
\hline \multicolumn{5}{|l|}{ Recent life events ( $\leq 1$ year) } \\
\hline Conjugal separation & 77 (13.6) & $16(11.0)$ & $61(14.5)$ & .147 \\
\hline Job loss & $51(9.0)$ & $8(5.5)$ & $43(10.2)$ & .082 \\
\hline \multicolumn{5}{|l|}{ Suicidal behaviours } \\
\hline Previous suicide attempt & $208(36.7)$ & $72(49.7)$ & $136(32.3)$ & .081 \\
\hline Previous suicide attempt within past year & $91(16.1)$ & $31(21.4)$ & $60(14.3)$ & .583 \\
\hline Suicidal verbalizations & $304(53.7)$ & 85 (58.6) & $219(52.0)$ & .185 \\
\hline Behavioural changes & $271(47.8)$ & $67(46.2)$ & $204(48.5)$ & .081 \\
\hline \multicolumn{5}{|l|}{ Recent health services utilization ( $\leq 1$ year) } \\
\hline At least 1 service & 339 (59.9) & $105(72.4)$ & $234(55.6)$ & .000 \\
\hline Family physician & $202(35.7)$ & $63(43.4)$ & $139(33.0)$ & .024 \\
\hline Psychiatrist & 157 (27.7) & $59(40.7)$ & $98(23.3)$ & .000 \\
\hline Psychologist & $23(4.1)$ & $10(6.9)$ & $13(3.1)$ & .045 \\
\hline \multicolumn{5}{|l|}{ Death circumstances } \\
\hline Suicide note & 246 (43.5) & 72 (49.7) & $174(41.3)$ & .110 \\
\hline Signs of planning & 117 (20.7) & 39 (26.9) & 78 (18.5) & .461 \\
\hline Death at home & 381 (67.3) & $110(75.9)$ & $271(64.4)$ & .012 \\
\hline \multicolumn{5}{|l|}{ Means of death } \\
\hline Strangulation & $259(45.7)$ & $41(28.3)$ & 218 (51.8) & .000 \\
\hline Poisoning & $130(22.9)$ & $61(42.1)$ & $69(16.4)$ & .000 \\
\hline Fall & $44(7.8)$ & $13(9.0)$ & $31(7.4)$ & .534 \\
\hline Firearm & $26(4.6)$ & $6(4.1)$ & $20(4.8)$ & .761 \\
\hline Drowning & $20(3.6)$ & $6(4.1)$ & $14(3.3)$ & .648 \\
\hline Subway & $19(3.4)$ & $4(2.8)$ & $15(3.6)$ & .643 \\
\hline Other & $68(12.0)$ & $14(9.6)$ & 54 (12.7) & .311 \\
\hline
\end{tabular}

attempted suicide-difficult for coroners to obtain.

The data collected by coroners in their investigations could prove highly useful in suicide prevention. Coroners have direct and privileged access to the family of the deceased and to additional sources of information, such as the police report, the toxicology report and the medical record. All these sources of information could help us better understand the circumstances surrounding deaths by suicide and develop a profile of suicide cases that could inform decision making around suicide prevention. Unfortunately, coroners' records are often incomplete sources of information. In almost half of the files, there is no information on prior suicide attempts or on recent events that may have precipitated the suicide, such as a conjugal separation or job loss. In contrast, diagnoses of mental disorders and a history of health services utilization are always available in coroner's files. One explanation may be that coroners adhere to a biomedical model in which suicide is seen as a medical complication of a mental illness. ${ }^{24}$ As previously mentioned, Montréal's coroners are mostly physicians. However, even if the coroners always investigate mental disorders, they seem to underestimate their prevalence. Almost two-thirds (63.1\%) of the files mentioned at least one disorder while this proportion ranged from $80 \%$ to $96 \%$ in psychological autopsies. $^{25,26}$ The same can be said of health service use in the year before the suicide: according to the coroners' records, $36 \%$ of the cases consulted a general practitioner in the year preceding their death, whereas this figure is between $76 \%$ and $86 \%$ in rigorous studies of the issue. ${ }^{27,28}$ A standardized data collection form that covers all the parameters relevant to preventing suicide would help to reduce the amount of missing data in coroners' records.

In the United States, the Centers for Disease Control and Prevention (CDC) have sponsored the development of a National Violent Death Reporting System (NVDRS). ${ }^{29,30}$ This active, state-based surveillance system collects risk factor data on all violent deaths, including homicides, suicides and unintentional fire- 
TABLE 3

Profiles of suicide cases in HSSC Area A and Area B, Montréal, Quebec, 2007-2009

\begin{tabular}{|c|c|c|c|}
\hline Characteristic & $\begin{array}{c}\text { Area A } \\
(\mathbf{n}=85) \\
n(\%)\end{array}$ & $\begin{array}{c}\text { Area B } \\
(\mathbf{n}=32) \\
\mathbf{n}(\%)\end{array}$ & $p$ value \\
\hline Sex (male) & $64(75)$ & $23(72)$ & .706 \\
\hline \multicolumn{4}{|l|}{ Age, years } \\
\hline $15-64$ & $74(87)$ & $24(75)$ & .115 \\
\hline$\geq 65$ & $11(13)$ & $8(25)$ & .113 \\
\hline \multicolumn{4}{|l|}{ Sociodemographic profile } \\
\hline Not cohabiting & $70(82)$ & $15(47)$ & .000 \\
\hline Unemployed & $48(57)$ & $18(56)$ & .956 \\
\hline Childless & $61(72)$ & $13(41)$ & .001 \\
\hline Living alone & $53(62)$ & $9(28)$ & .001 \\
\hline Financial problems & $35(41)$ & $4(13)$ & .005 \\
\hline Criminal record & $20(24)$ & $2(6)$ & .033 \\
\hline \multicolumn{4}{|l|}{ Mental disorders } \\
\hline At least 1 disorder & $55(65)$ & $16(50)$ & .145 \\
\hline Depression & $27(32)$ & $12(38)$ & .557 \\
\hline Substance abuse & $31(37)$ & $2(6)$ & .001 \\
\hline Bipolar disorder & $5(6)$ & $1(3)$ & .547 \\
\hline Schizophrenia & $12(14)$ & 1 (3) & .092 \\
\hline \multicolumn{4}{|l|}{ Suicidal manifestations } \\
\hline Previous suicide attempt & $44(52)$ & $8(25)$ & .001 \\
\hline Previous suicide attempt within past year & $20(24)$ & $2(6)$ & .085 \\
\hline Suicidal verbalizations & $49(58)$ & $21(66)$ & .667 \\
\hline Behavioural changes & $35(41)$ & $16(19)$ & .874 \\
\hline \multicolumn{4}{|c|}{ Recent health services utilization (within past year) } \\
\hline At least 1 service & $53(62)$ & $17(53)$ & .364 \\
\hline Family physician & $30(35)$ & $11(34)$ & .926 \\
\hline Psychiatrist & $22(26)$ & $8(25)$ & .922 \\
\hline Psychologist & $6(7)$ & $3(9)$ & .675 \\
\hline \multicolumn{4}{|l|}{ Death circumstances } \\
\hline Suicide note & $40(47)$ & $11(34)$ & .181 \\
\hline Signs of planning & $12(14)$ & $9(28)$ & .754 \\
\hline Death at home & $63(74)$ & $21(66)$ & .363 \\
\hline \multicolumn{4}{|l|}{ Suicide method } \\
\hline Strangulation & 32 (38) & $15(47)$ & .364 \\
\hline Poisoning & 32 (38) & $4(13)$ & .009 \\
\hline Fall & $12(14)$ & $0(0)$ & .025 \\
\hline Firearm & $2(2)$ & $3(9)$ & .094 \\
\hline Drowning & $0(0)$ & $2(6)$ & .020 \\
\hline
\end{tabular}

Abbreviation: HSSC, Health and social services centre.

arms deaths. The detailed information stored in the system is used to help develop, implement and evaluate strategies designed to reduce and prevent violence-related deaths. Precipitating circumstances are particularly carefully investigated (e.g. mental health diagnoses and treatment, substance abuse problems, interpersonal problems involving intimate partners, recent deaths in the family or among friends, financial problems, interpersonal violence, etc.). ${ }^{31}$ This tool could also prove highly useful in developing more comprehensive and structured investigation forms for use by coroners in Quebec.

Improving the quality of the data collected by coroners and making it more complete will not, however, guarantee its use by local decision makers, who do not currently have access to this information. To alleviate this problem, work has begun on a regional observatory of attempted and completed suicide in Montréal. Suicide Action Montréal and the Centre for Research and Intervention on Suicide and Euthanasia (CRISE) of the Université du Québec à Montréal will be jointly responsible for the observatory. The observatory will access all available data on people who died by suicide (including data from the Coroner's Office and administrative data about physician claims and hospitalization). This data will be anonymized and securely stored to protect personal information. A team of researchers will have a mandate to regularly produce useful local profiles for the program's decision makers and planners. With infrastructure in place dedicated to making use of the data collected by coroners, we can expect this information to lead to improvements in targeted suicide-prevention strategies.

The large variance in suicide rates in the 12 HSSC areas in Montréal is undoubtedly due in part to the great social diversity of this city. This study is unique in that we were able to develop different profiles of the suicide cases in two HSSC areas: in Area A, with the highest suicide rate, suicide cases are often socially isolated and have a substance abuse problem, while in Area B, with the lowest suicide rate, a higher number of suicide cases appear to be socially well integrated and their rate of substance abuse is low. However, these data should be interpreted with caution because of the low number of cases $(n=117)$, particularly in the area with the lowest suicide rate $(n=32)$. The findings nonetheless suggest that distinct preventive actions could be taken with these two subpopulations to improve the effectiveness of suicide-prevention strategies. If HSSC mental health teams had better knowledge of the characteristics of 
suicide cases in their area, they could adjust their interventions accordingly, for example, by monitoring people more closely when they present a specific risk profile.

\section{Strengths and limitations}

By analyzing coroners' records, we have expanded our knowledge of suicide cases in Montreal from 2007 to 2009. However, the originality of the study lies not only in the fact that we have revealed shortcomings in the process used to investigate deaths by suicide, but also in that we have shown the potential positive implications of being able to have detailed and valid local data.

However, several factors limit the conclusions that can be drawn from this study. First, by using coroners' files as our only source of data, the results are limited by the uneven quality of the compiled information and the absence of some important information. In order to obtain a fuller and more accurate profile, it would have been necessary to perform psychological autopsies. This research procedure consists of conducting structured interviews with the family and friends of suicide cases to accurately establish the person's physical and mental state at time of death and investigate the circumstances leading up to their death. Had we used the administrative databases of Quebec's health insurance authority (the Régie de l'Assurance maladie du Québec), we could have also described with certainty the person's use of medical resources in the year leading up to their death. We could have also confirmed or added certain diagnoses of mental health problems. For reasons of feasibility and due to the exploratory nature of this study, we limited our analysis to a three-year period. Great care should be exercised when interpreting the results from areas that had few suicides during this period.

\section{Conclusion}

Almost all decisions to do with implementing suicide-prevention actions are made at the local level. HSSCs play a key role by developing services for their client base and ensuring that their actions are co-ordinated with those of all their community-based partners. In order to be effective in this role, HSSCs need detailed data on suicide cases in their areas. With its 12 HSSCs, Montreal has a very heterogeneous population. Our study has shown that this diversity can also be seen in geographic variations in local profiles of suicide cases. General profiles of the entire population of Montreal are of limited use to decision makers. We need to go beyond general findings and provide them with more detailed information.

The scale of suicide and its tragic consequences for thousands of Canadians each year requires the strongest possible actions, and coroners have an important role to play in reducing suicide rates by helping us better understand the causes of suicide. They can help greatly advance knowledge in this area by applying a systematic, standardized data collection procedure to suicide cases. Such knowledge may lead to better targeted and more effective actions in at-risk individuals.

\section{Acknowledgements}

This study has been made possible by financial support from Suicide Action Montréal and the Centre for Research and Intervention on Suicide and Euthanasia (CRISE). The authors would like to thank Carole Renaud, who collected data at Quebec's Coroner's Office, and Francis Allard, who verified all the results. PaulAndré Perron of the Chief Coroner's Office as well as Philippe Angers and Véronique Landry of Suicide Action Montréal read the report and provided their comments. We would also like to thank Charles Cardinal, librarian at the Centre for Research and Intervention on Suicide and Euthanasia, for his invaluable support in the literature review.

\section{References}

1. Statistics Canada. Mortality, summary list of causes: 2000. Ottawa (ON): Statistics Canada, Health Statistics Division; 2006 [Statistics Canada, Catalogue No.: 84F0209XIE].
2. Statistics Canada. Mortality, summary list of causes: 2009. Ottawa (ON): Statistics Canada, Health Statistics Division; 2012 [Statistics Canada, Catalogue No.: 84F0209X].

3. Gagné M, Saint-Laurent D. La mortalité par suicide au Québec: tendances et données récentes, 1981 à 2008. Direction, recherche, formation et développement. Québec (QC): Institut national de santé publique; 2012. 19 p. [INSPQ, Publication No.: 890].

4. Mann JJ, Apter A, Bertolote J, et al. Suicide prevention strategies: a systematic review. JAMA. 2005 Oct;294(16):2064-74.

5. Erlangsen A, Nordentoft $\mathrm{M}$, Conwell $\mathrm{Y}$, et al. Key considerations for preventing suicide in older adults. Crisis. 2011;32(2): 106-9.

6. Davis SP, Arnette NC, Bethea KS, et al. The Grady Nia Project: A culturally competent intervention for low-income, abused, and suicidal African American women. Prof Psychol Res Pr. 2009:40(2):141-7.

7. Nordentoft M. Crucial elements in suicide prevention strategies. Prog Neuropsychopharmacol Biol Psychiatry. 2011;35(4): 848-53.

8. Schwartz-Lifshitz M, Zalsman G and Giner L. Can we really prevent suicide? Curr Psychiatry Rep. 2012;14(6):624-33.

9. De Leo D, Dello Buono MD, Dwyer J. Suicide among the elderly: the long-term impact of a telephone support and assessment intervention in northern Italy. $\mathrm{Br} \mathrm{J}$ Psychiatry. 2002;181:226-9.

10. Mishara BL, Martin N. Effects of a comprehensive police suicide prevention program. Crisis. 2012;33(3):162-8.

11. Knox KL, Litts DA, Talcott GW, Feig JC, Caine ED. Risk of suicide and related adverse outcomes after exposure to a suicide prevention programme in the US Air Force: cohort study. BMJ. 2003; 327:1376.

12. Knox KL, Pflanz S, Talcott GW, et al. The Air Force suicide prevention program: implications for public health policy. Am J Public Health. 2010;100(12):2457-63. 
13. Ostry AS. The mortality gap between urban and rural Canadians: a gendered analysis. Rural Remote Health. 2009;9(4):1286.

14. Taux de mortalité par suicide, Montréal, CSSS et CLSC, 2005-2009. Montreal (QC): Direction de santé publique de Montréal; 2009.

15. Lane J, Archambault J, Collins-Poulette M, Camirand R. Prévention du suicide: guide des bonnes pratiques à l'intention des intervenants des centres de santé et de services sociaux. Québec (QC): Direction des communications, Ministère de la santé et des services sociaux; 2010.

16. Agence de la santé et des services sociaux de Montréal. Regard local sur la défavorisation et le suicide. Présentation dans le cadre des ateliers de gestionnaires sur l'implantation du Guide de bonnes pratiques en prévention du suicide à l'intention des gestionnaires des Centres de santé et de services sociaux et des réseaux locaux de services. Montréal (QC): Agence de la santé et des services sociaux de Montréal; 2012.

17. Act respecting the determination of the causes and circumstances of death. LRQ, 1983. c.4, a.2.

18. St-Laurent D, Bouchard C. L'épidémiologie du suicide au Québec: que savons-nous de la situation récente? [Internet]. Québec (QC): Institut national de santé publique du Québec; 2004 [cited 2013 Dec 9]. 24 p. Available from: http://www.inspq.qc.ca

19. Guindon M. Quartiers à la loupe: un portrait pour l'action. Portrait de la population du territoire du CSSS Jeanne-Mance. Montréal (QC): Centre de santé et de services sociaux; 2009, $24 \mathrm{p}$.

20. Centre de santé et de services sociaux de l'Ouest-de-l'île. Snapshot of the West Island HSSC. Pointe-Claire (QC): West Island Health and Social Services Centre; 2010. Available from: http://www.csssouestdelile .qc.ca/fileadmin/csss_odi/publications /Portrait_du_CSSS/brochureMars2010_ portrait_CSSS.pdf

21. Boileau JC, Corriveau-Durand S, Grondines L, Lamoureux-Auclair A, Morin-Ben Abdallah S. Analyse des rapports des coroners des décès par suicide en Estrie: profils et recommandations. Centre de santé et de services sociaux, Institut universitaire de gériatrie de Sherbrooke. Sherbrooke (QC); 2011. 61pp.
22. Campbell LA, Jackson L, Bassett R, et al. Can we use medical examiners' records for suicide surveillance and prevention research in Nova Scotia? Chronic Dis Inj Can. 2011 Sep;31(4):165-71.

23. Powell V, Barber CW, Hedegaard $\mathrm{H}$, et al. Using NVDRS data for suicide prevention: promising practices in seven states. Inj Prev. 2006;12 (Suppl II): ii28-32.

24. Mishara BL, Chagnon F. Understanding the relationship between mental illness and suicide and the implications for suicide prevention. In: O'Connor RC, Platt S, Gordon J, editors. International handbook of suicide prevention: research, policy and practice. Chichester (UK): John Wiley \& Sons Ltd; 2011. p. 609-623.

25. Canavagh JT, Carson AJ, Sharpe M, Lawrie SM. Psychological autopsy studies of suicide: a systematic review. Psychol Med. 2003;33(3):395-405.

26. Arsenault-Lapierre G, Kim C, Turecki G. Psychiatric diagnoses in 3275 suicides: a meta-analysis. BMC Psychiatry. 2004; 4:37.

27. Luoma JB, Martin CE, Pearson JL. Contact with mental health and primary care providers before suicide: a review of the evidence. Am J Psychiatry. 2002; 159(6):909-16

28. Morrison KB, Laing L. Adults' use of health services in the year before death by suicide in Alberta. Health Rep. 2011 Sep;22(3):1522. [Statistics Canada, Catalogue No.: 82003-XIE].

29. Paulozzi LJ, Mercy J, Frazier L Jr, Annest JL. CDC's National Violent Death Reporting System: background and methodology. Inj Prev. 2004;10(1):47-52.

30. Steencamp M, Frazier L, Lipskiy N, et al. The National Violent Death Reporting System: an exciting new tool for public health surveillance. Inj Prev. 2006; 12(Suppl 2):ii3-5.

31. CDC. National Violent Death Reporting System (NVDRS) Coding Manual Version 3 [Internet]. National Center for Injury Prevention and Control, Centers for Disease Control and Prevention; 2008 [cited 2013 Dec 9]. Available from: http:// www.cdc.gov/ncipc/pub-res/nvdrs-coding /vs3/nvdrs_coding_manual_version_3-a.pdf 